\title{
Carbon Emission and Economic Growth Model of Beijing Based on Symbolic Regression
}

\author{
Lei Wen*, Qiao Li, Yue Li, Zeyang Ma \\ Department of Economics and Management, North China Electric Power University, \\ Baoding, Hebei 071003, China
}

Received: 28 February 2017

Accepted: 28 May 2017

\begin{abstract}
With the continuous improvement of the economy, more and more attention has been paid to environmental problems. Beijing is China's economic, political, and cultural center, and its low-carbon development by external concerns. In this paper, the relationship between economic development and environmental pollution is analyzed by using the symbolic regression method, which is based on the data of per capita $\mathrm{CO}_{2}$ emissions, total energy consumption, energy intensity, and per capita GDP in Beijing city during 1980-2015. The study found that the presence of the M-curve model between per capita $\mathrm{CO}_{2}$ emissions and per capita GDP, total energy consumption, and per capita GDP are in line with the traditional model of the EKC curve, and that the L-curve model exists between the energy intensity and per capita GDP, respectively, with promising performance. Based on our analysis, we present policy suggestions for reducing carbon emissions and developing a low-carbon economy in Beijing.
\end{abstract}

Keywords: carbon emissions, symbolic regression, EKC curve, M-curve model, L-curve model

\section{Introduction}

Since the reform and opening up policy began, the economy of China has been growing at a high speed for a long time. At the same time, however, environmental quality is deteriorating and air pollution in recent years is still an issue. As the largest developing country, China is still in the stage of rapid industrial development and urbanization, and the total amount of carbon emissions is still growing. In 2009 China surpassed the United States to become the largest energy consumer in the world [1]. In the face of pressure, at the Copenhagen global climate conference in 2009 China first proposed emission

*e-mail: 731619776@qq.com reduction targets for decreasing carbon dioxide intensity by $45 \%$ from 2005 to 2020 . It is also a binding index to the plan in the $12^{\text {th }}$ Five-Year Plan. In November 2015, as part of the $13^{\text {th }}$ Five-Year Plan proposal, China further emphasized the development of the low-carbon cycle and improving the ecological environment.

The Beijing-Tianjin-Hebei Synergistic Development Plan, approved in May 2015, suggested that the core of Beijing-Tianjin-Hebei coordinated development strategy is to ease Beijing's non-capital function and adjust economic and spatial structures to realize regional superiority complementarity and benign interaction. Beijing, as the capital of China, is the economic, political, and cultural center of the country, has strong research and development capabilities and innovative ability, and its modern service industry is very developed. In 2015 the ratio of the three 
industrial structures in Beijing was 0.6:19.7:79.7, and it entered the post-industrialization development period [2-4]. Its low-carbon development is of concern to the outside world. While maintaining economic growth, controlling the growth of carbon emissions is an important issue [5-8].

The relationship between environmental quality and economic development is commonly described by the environmental Kuznets curve (EKC) as an inverted U-shaped curve. The Kuznets curve was proposed by American economist Kuznets [9] to describe the distribution of income changes with the economic development process. In the early 1990 s, scholars began to introduce the Kuznets curve into the relationship between the environment and economic growth [10-11]. Grossman and Krueger [12] proposed that the relationship between environmental quality and economic development also exists as an inverted U-shaped curve. The EKC hypothesis reveals that the quality of the environment will deteriorate with the increase of per capita income [13-14]. When economic development reaches a certain stage, with the increase of per capita income, environmental pollution will gradually improve.

There are many empirical studies that use EKC theory to investigate the relationship between environmental degradation and economic growth. Some scholars through the study discover that per capita GDP and per capita carbon emissions exist as inverted U-shaped curves [1516]. While Stern [17] and Ansuategi and Escapa [18] argue that the hypothesis does not apply to global environmental indicators, there will be a synchronous relationship in the analysis of global environmental indicators. Several studies have noted that in addition to the inverted U-shaped model there exists an $\mathrm{N}$-shaped model and monotonically increasing model to explain the relationship [19-20]. In general, there is a certain relationship between economic growth and environmental pollution [21-22]. The EKC curve provides a great degree of reference for our research.

The core method used in this paper is symbolic regression, which is based on evolutionary computation, also known as function modeling [23]. According to a given set of independent variables and a set of function values, it shows the fit function relationship by using the symbolic regression method. Symbolic regression has been applied successfully in many fields. Schmidt and Lipson [24] used symbolic regression to search for motion tracking data automatically and found the Hamiltonian, Lagrangian, and other laws of geometric and momentum conservation. Kotanchek et al. [25] detected outliers and extracted significant features from the country data by using symbolic regression as a discovery engine covering economic, political, social, and geographic areas. Yang et al. [26] applied the symbolic regression method to study the nexus between environmental quality and economic growth and discovered that four models - including nverted N-shaped, M-shaped, inverted U-shaped, and monotonically increasing - exhibit promising performance.

\section{Materials and Methods}

\author{
Symbolic Regression Method
}

In this paper, the relationship between environmental pollution and economic growth in Beijing has been studied on the basis of the relevant theory of EKC by means of symbolic regression.

The symbolic regression method is built upon genetic programming (GP) [27-28], which is an extension of a genetic algorithm. GP is a kind of automatic programming technology [29] produced and developed in recent years with the automation of programming. The basic principle of GP is to generate an initial population as a search space according to the given problem. Each individual in the population is a dynamic tree structure with a certain fitness value [30]. According to the Darwinian theory of evolution, the individuals with high fitness will produce the next generation of the population in the process of evolution, and the optimal solution of the given problem will appear in a certain generation [31].

Compared with the traditional methods, the symbolic regression method does not need to assume any functional form [32-33] that avoids the reduction of the range of selection caused by the prior hypothesis model, and reduces the possibility of missing the potential model. The function set of symbolic regression mainly includes arithmetic operators $(+,-, *, /)$ and mathematical functions (sin, cos, log, exp), etc. The terminal set includes different types of variables and constants that indicate the most basic elements of the problem and the results [34-35]. Fitness is the basis for evaluating the merits of individuals. Individuals with high fitness are retained, and low-fitness individuals are eliminated.

The genetic operators of GP mainly include reproduction, crossover, and mutation [36]. Replication is the selection of individuals in the previous generation directly into the next generation. The more fit the individual, the greater the probability of inheritance to the next generation. The crossover operator chooses two individuals randomly from the current population as the parent individual according to the fitness value of the individual, and then exchanges the partial genes of the two parent individuals to form new offspring individuals. The crossover operator enlarges the search range of the candidate solution and improves the whole optimization ability in the evolution process. Mutation simulates genetic mutations in the biosphere. For an individual in the current population, the mutation operator chooses randomly any node other than the root as a mutation point, and then generates a new subtree to replace the subtree under the mutation point to produce a new individual.

The advantage of symbolic regression is that it can efficiently find models and parameters with higher accuracy [37-38]. Generally, the more complex candidate solutions may be more accurate, but the probability of over-fitting will also increase. A simple and effective method to control the over-fitting problem is to limit the model complexity. In this paper, $\mathrm{C}$ is used to represent the 


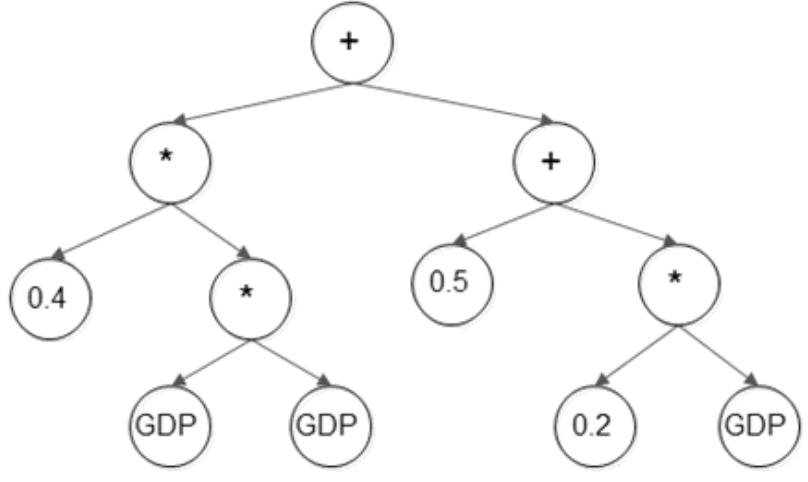

Fig. 1. An example of tree structure in symbolic regression for the expression $0.4 * \mathrm{GDP}^{2}+0.2 * \mathrm{GDP}+0.5$.

complexity of the candidate solution. In the tree structure, each node represents the complexity of 1 by measuring the total number of nodes in the syntax tree, which makes the candidate model complex. For example, the complexity of the solution in Fig. 1 is 11.

It is normal to use the mean absolute error (MAE) of the evolutionary process and the total number of nodes in the syntax tree as two common indicators in the process of symbolic regression. According to Occarn's razor, when two theories with the same explanatory power are in competition, the simpler one is better, that is, under the same precision, the model with lower complexity is better. While the Pareto front can effectively balance the accuracy and complexity of the fitting process [39-40]. Based on the mean absolute error and complexity, the Pareto front is further selected from the millions of candidate solutions. When models have the same complexity, the computer will select the candidate solutions with higher precision, and the candidate solutions with lower complexity will be selected if models have a similar fitting accuracy. So the Pareto optimal solution is helpful to further findings that are the suitable candidate solutions from the millions of candidate models. The Pareto diagram is shown in Fig. 2, the solution of high precision and complex appears in the lower right corner, simple but low precision solutions in the upper left, the most effective candidate

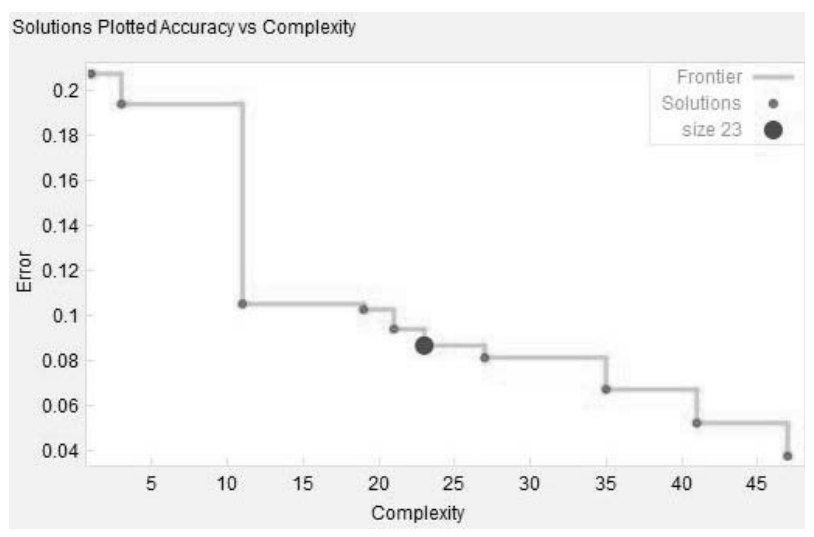

Fig. 2 Pareto chart. is usually located in the middle part, reached a balance between complexity and accuracy.

In this paper, fitting accuracy is measured by fitness measure R-squared $\left(R^{2}\right)$, calculated as in Eq. (1), where $Y_{i}$ is the actual value of the dependent variable, $\hat{Y}_{i}$ indicates the predictive value, and $\bar{Y}$ is the average value of the dependent variable.

$$
R^{2}=1-\frac{\sum\left(Y_{i}-\hat{Y}_{i}\right)^{2}}{\sum\left(Y_{i}-\bar{Y}\right)^{2}}
$$

The Eureqa Formulize is used to solve the modeling problem of symbolic regression. Eureqa is a scientific data mining software package that automates much of the heavy lifting inherent in analytics and data science. Leveraging automated evolutionary algorithms, Eureqa churns through the data to create accurate predictive models.

\section{Data Sources}

In general, the selection of different variables as an indicator of environmental pollution and economic growth will affect the final results. In this paper, the per capita GDP has been selected as the representative of economic growth, the per capita $\mathrm{CO}_{2}$ emission, total energy consumption, and energy consumption intensity are taken as the main environmental quality indicators. And the data of per capita GDP, total energy consumption, energy intensity, and per capita $\mathrm{CO}_{2}$ emission of Beijing from 1980 to 2015 has been selected to study the relationship between carbon emissions and economic growth. The data are derived from the Beijing Statistical Yearbook and the China Energy Statistical Yearbook. The calculation of the total carbon dioxide emissions is based on the methodology in the IPCC Guidelines for National Greenhouse Gas Inventories [41].

In order to make the data comparable, this paper uses SPSS software to normalize all the variables by Z-score, as shown in Eq. (2), where $\mu$ is the mean of all the sample data and $\sigma$ is the standard deviation. In order to facilitate symbolic regression modeling, the indicators of the per capita GDP is denoted by GDP, total energy consumption is expressed by TEC, energy intensity is expressed by EI, and per capita $\mathrm{CO}_{2}$ emission is denoted by $\mathrm{CO}_{2}$.

$$
z=\frac{x-\mu}{\sigma}
$$

\section{Results and Discussion}

\section{Experimental Results}

In the study of the relationship between per capita $\mathrm{CO}_{2}$ emissions, total energy consumption, energy intensity, and 
Table 1. Relationship between carbon emissions and economic development models of Beijing.

\begin{tabular}{|c|c|c|c|}
\hline Model & $C$ & $R^{2}$ & MAE \\
\hline$C O_{2}=0.3859+G D P^{2}+1.5007 * G D P^{3}+0.5272 * G D P^{5}-2.0465 * G D P^{4}$ & 35 & 0.955 & 0.154 \\
\hline$T E C=0.1476+0.8248 * G D P+0.3955^{*} G D P^{3}-0.2077 * G D P^{4}$ & 23 & 0.983 & 0.087 \\
\hline$E I=0.4441 * G D P+1.5761 * G D P^{4}-0.6611-0.3594 * G D P^{5}-1.8281 * G D P^{3}$ & 35 & 0.929 & 0.186 \\
\hline
\end{tabular}

per capita GDP by the method of symbolic regression, the model is shown in Table 1, and the curve model is shown in Fig. 3. In these statistical models, the coefficients of all variables are positive.

Based on Table 1 and Fig. 3, it could be observed that:

1. For the study of the relationship between environmental pollution and economic growth, there are differences between different environmental indicators in finding the model with per capita GDP by using the symbolic regression method. And even for the same index, using different measurement methods, the curve models will be different.

2. When the per capita $\mathrm{CO}_{2}$ emissions and per capita GDP are chosen as indicators, it is found that Beijing is fit with an M-shaped curve quite well, which is less mentioned in the previous literature. In the selection of total energy consumption and per capita GDP as indicators, the Beijing area is in accordance with the apparent inverted U-shaped curve. When the energy intensity and per capita GDP are used as the research index, a new L-shaped curve is found to explain the relationship between the environment and the economy. Although the L-shaped curve is rarely mentioned in the previous literature, it can be a good fit to describe the relationship between the change of energy intensity and economic growth.

3. The model with high R-squared has a strong ability to describe the relationship in general. As shown in Table 1 , the three models of Beijing are more than 0.9 and below the complexity of 40 to explain their respective indicators. Among them, the R-squared of the inverted U-shaped curve model surpasses 0.98 and the MAE does not exceed 0.1 . The M-shaped curve model has an R-squared value of 0.955 and the L-shaped curve model has an R-squared value of 0.928 . All of them have strong explanatory power.

\section{Analysis of M-shaped Curve}

The M-shaped curve is a new model found in the study of the relationship between per capita $\mathrm{CO}_{2}$ emissions and per capita GDP. The curve model is seldom mentioned in the previous literature, which could be subdivided into four stages according to the trend, as described in Fig. 3a):

First stage. From 1980 to 1993, after the reform and opening up in 1978, Beijing entered the fastest historical period of economic growth and industrialization. In this period, the economic development was industrycentered, in which heavy industry accounted for a large proportion, and the secondary industry accounted for $68.9 \%$ of GDP. Metal products, petroleum processing, and other industries accounted for a large proportion. Rapid economic development has also led to the growth of carbon emissions. As a result, Beijing has become one of the 10 most polluted cities in the world. Per capita GDP and per capita $\mathrm{CO}_{2}$ emissions have increased (see Fig. 4), and the relationship curve shows an upward trend.

Second stage. From 1994 to 2000, this stage is the period of strategic adjustment of industrial structure in Beijing, during which Beijing began to develop the tertiary industry and modern service industry, the proportion of the tertiary industry is rising rapidly, and the proportion of primary industry and secondary industry with large environmental pollution is decreasing (see Fig. 5). Therefore, environmental quality has been improved to a certain extent. During this period, the manufacturing
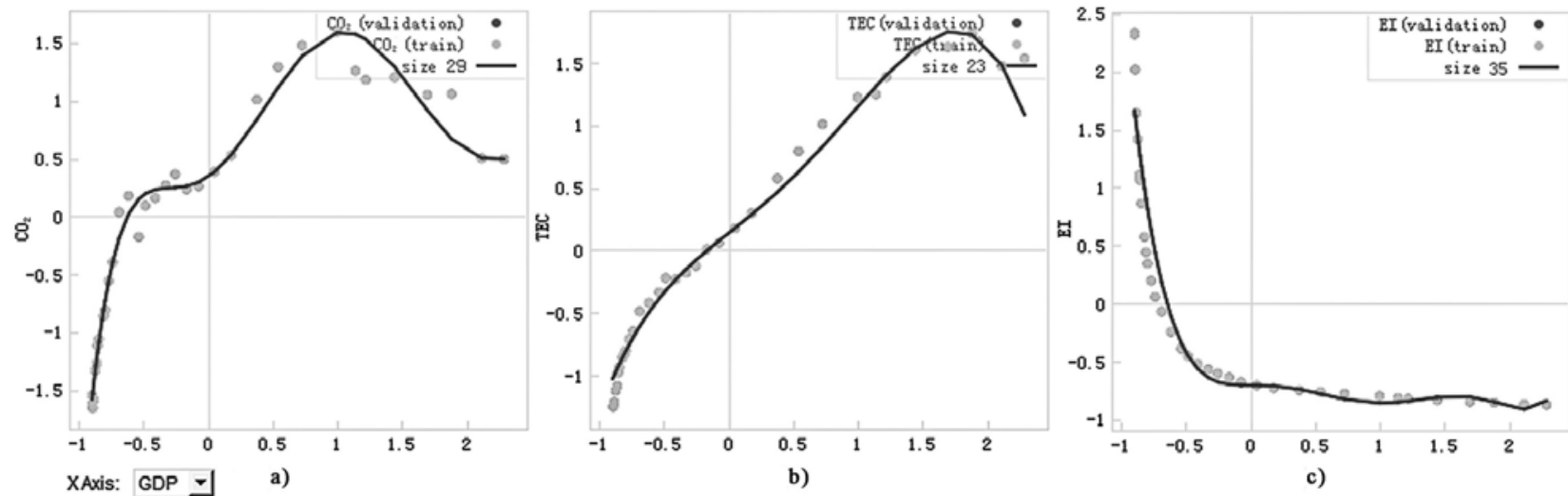

Fig. 3 The curve of carbon emissions and economic development in Beijing. 


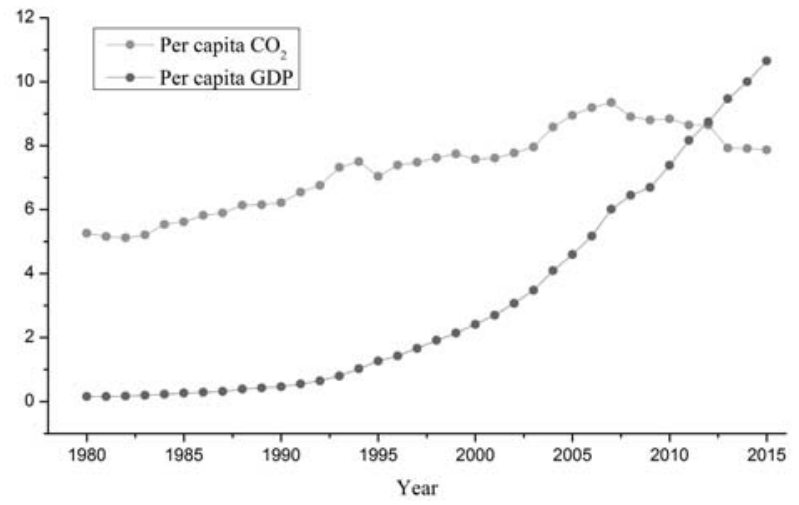

Fig. 4. Per capita GDP and per capita $\mathrm{CO}_{2}$ emissions in Beijings.

industry in the proportion of GDP in the large-scale decline has accelerated the increasing proportion of tertiary industry's rapid increase. In 1995 the tertiary industry accounted for more than 50\%, and Beijing established the "tertiary, secondary, primary" of the industrial structure order. Compared with 1994, the proportion of primary industry and secondary industry decreased by $57.63 \%$ and $27.65 \%$, respectively, and the tertiary industry increased by $32.52 \%$ in 2000 . The per capita $\mathrm{CO}_{2}$ emissions fluctuated slightly while keeping the per capita GDP increasing. The curve model shows a downward trend.

Third stage. From 2001 to 2007 this stage is the period of accelerated industrialization in China, with heavy industry - especially the high energy consumption industries - flourishing, which leads to an increase in total energy consumption and carbon dioxide emissions. During this period, the per capita GDP of Beijing increased rapidly, which in 2007 was 1.5 times that of 2000. The proportion of the primary industry and secondary industry decreased by $54.45 \%$ and $17.21 \%$, respectively, and tertiary industry increased by $9.70 \%$. Compared with the previous stage, the growth rate of the tertiary industry has declined. Beijing has also implemented a series of measures to improve the environment in a bid to host the Olympic Games. From May to July 2006 the Beijing Shougang No. 2 coke oven and coking chemical plant were discontinued,

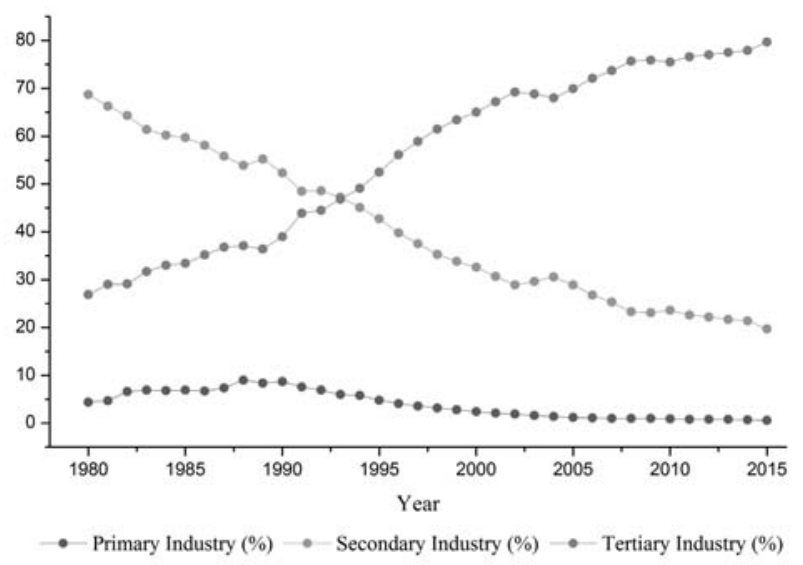

Fig. 5. Three industrial structure change chart in Beijing. and the five coal-fired power plants in accordance with the requirements of the preparation of the Olympic Games carried out deep governance projects. However, in general the per capita $\mathrm{CO}_{2}$ emissions show an increasing trend year by year, and the relationship between per capita GDP and $\mathrm{CO}_{2}$ emissions shows a rising trend again.

Fourth stage. From 2008 to 2015 Beijing improved the intensity of environmental governance due to the hosting of the 2008 Olympic Games, and has achieved remarkable results in reducing carbon emissions. The overall shutdown of Beijing Shougang in 2010 also had a positive impact on the environment. The per capita $\mathrm{CO}_{2}$ emissions began to show a falling trend starting in 2008 . The per capita $\mathrm{CO}_{2}$ emissions from the beginning of 2008 overall showed a downward trend, and the proportion of the tertiary industry increased to $77.9 \%$ and continues to maintain a steady growth trend. High-tech industry, modern service industry, and other low-carbon industries occupy a dominant position, a favorable industrial structure inhibited the growth of carbon emissions, and the relationship between per capita $\mathrm{CO}_{2}$ emission and per capita GDP emerges in a downward trend.

Beijing has been aware of the problem of economic growth and environmental pollution and will pay more attention to carbon emissions factors in the future. Under the strict control of the government, the curve between per capita $\mathrm{CO}_{2}$ and per capita GDP will also become more and more flat, and this steady development trend needs to be further consolidated.

\section{Analysis of Inverted U-shaped Curve}

The inverted U-curve is found in the study of the relationship between total energy consumption and per capita GDP. It is a traditional empirical model, reflecting that environmental quality deteriorates first and then improves with the development of the economy, as shown in Fig. $3 b$.

Total energy consumption in general is to maintain an upward trend from 1980 to 2012 in Beijing, as shown in Fig. 6. Since 1985 the proportion of Beijing's energy consumption in the country has been on the rise, and Beijing became the second largest energy consumption city in China, after Shanghai. Before 1997 the growth of energy consumption was steady and kept at an annual growth rate of $5 \%$. The Asian financial crisis had a certain impact on domestic economic growth in 1997 and the growth rate of energy consumption decreased, with a slow growth rate of $2 \%$ and even a $0.4 \%$ decline in 1997 . After China joined the WTO in 2001, the economic growth began to favor heavy industrialization. The total energy consumption in Beijing gradually began to increase significantly, increasing by $10.57 \%$ in 2004 . In 2008 China introduced a series of policies to eliminate some of the high energy consumption and high-polluting factories, coupled with the impact of financial crisis, total energy consumption only increased by $0.67 \%$ over the previous year. The annual growth rate of energy consumption from 2008 to 2012 tends to be slow. In 2013, with the rapid 


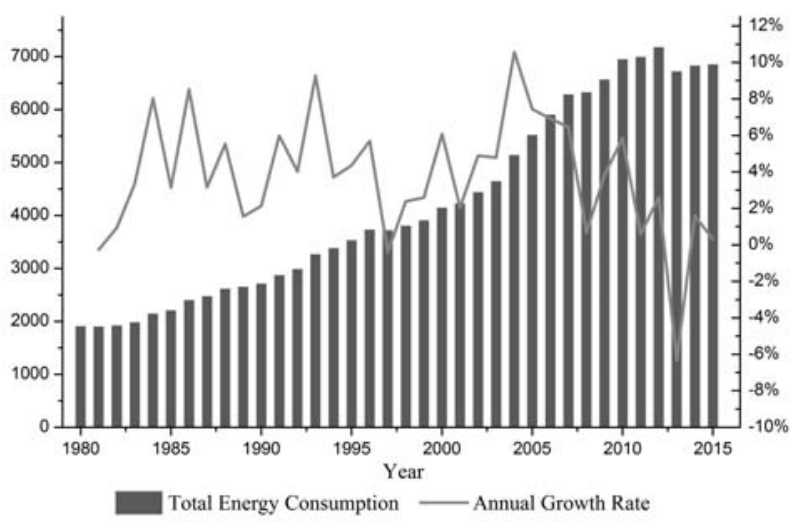

Fig. 6. Total energy consumption change chart in Beijing.

growth of per capita GDP, total energy consumption began to decline, which is $6.32 \%$ lower than that of 2012 . Although energy consumption fluctuated slightly in 2015, the relationship between per capita GDP and total energy consumption has been declining.

According to the EKC model, the growth relationship between total energy consumption and per capita GDP has reached the peak point. The environment of Beijing has begun to improve, and the trend of the decline will be maintained in future development.

\section{Analysis of L-shaped Curve}

The L-shaped curve is found in the study of the relationship between energy intensity and per capita GDP, which has received little attention in previous literature. As shown in Fig. 3c), the model is also divided into two stages:

1. Energy consumption intensity continued to decline due to changes in industrial structure and the rational allocation of resources caused by the efficiency of the increase. From 1980 to 2000, the energy intensity of Beijing was always high. In 1980, coal consumption accounted for about $70 \%$ of total energy, and energy consumption was excessively dependent on coal. With continuous improvement of the economy, energy efficiency increased and energy intensity continued to decline rapidly. In 2000 the energy intensity of Beijing was 1.31, a significant drop from 13.72 in 1980 .

2. When economic growth reaches a certain level, energy intensity fluctuates slightly with the change of total energy consumption. After 2000 the decline rate of Beijing's energy consumption intensity began to slow down in a few years and there was a small fluctuation. After 2000 the rate of decline in Beijing's energy intensity began to slow down with a small fluctuation in some specific years. In 2015 the energy intensity of Beijing was 0.33 , significantly lower than the national average of 0.67 , showing that energy efficiency has been evidently improved. At this stage, although energy consumption is in a state of continuous growth, because GDP growth is greater than the growth rate of energy consumption, the overall energy intensity shows a slow decline trend year by year. It can be seen that when a region's economy develops to a certain extent, the energy intensity will remain at a stabilized low level and the improvement of energy efficiency will become more difficult.

\section{Development Strategies for Beijing}

Based on the results drawn in this study, the following suggestions for the development of Beijing are proposed:

1. Optimize the industrial structure, increase the proportion of tertiary industry

The Beijing-Tianjin-Hebei region is one of the areas in China with a large population, strong scientific and technological innovation capability, and highly concentrated industrial clusters. In the context of economic integration, future development planning in Beijing should be based on new strategic positioning, mainly to play the role of scientific and technological innovation center to strengthen regional cooperation between a clear division of labor and industrial layout, while retaining Beijing as the capital of the national political center, cultural center, international contact center, and the core functions of science and technology innovation center by phasing out and transferring high energy-consuming and polluting industries such as iron and steel, machinery, non-ferrous metals, and chemicals.

Beijing is a typical knowledge and service area, has a wealth of talent and technology advantages, and has a welldeveloped high-end service industry. In 2015 the ratio of the three industrial structures in Beijing was 0.6:19.7:79.7, and its industrial structure has changed from the industryled to the service-oriented. As a developing country, China's lack of financial and technical conditions makes it difficult in the short term without prejudice to the premise of economic growth through the development of tertiary industry transformation and upgrading. So Beijing should continue to follow the development of the sophisticated industry and take the modern service industry to the first place while meanwhile focusing on upgrading the core competitiveness of industries and independent innovation capability. It is estimated that by 2020 the proportion of tertiary industry in Beijing will reach $82 \%$. The regional coordinated development will achieve remarkable results, and innovation-driven development will take shape.

2. Adjust the energy structure, develop and utilize new energy and renewable energy

Energy consumption structure determines the degree of carbon emissions of greenhouse gases to some extent. The existing coal-based energy consumption structure of Beijing is unreasonable, with a large amount of primary energy consumption resulting in $\mathrm{CO}_{2}$ emissions and hindering low-carbon economic development. Therefore, adjusting the energy structure and developing and utilizing renewable energy and new energy is a practical problem that must be dealt with at the present stage in Beijing.

Beijing has fewer energy storage and high dependence on external energy. Due to the restriction of geographical 
conditions and economic conditions, gradually reducing the total amount of coal and increasing the utilization rate of fossil fuels are important means to control carbon emissions by strengthening the development and utilization of clean energy, improving research and development of low-carbon technology, establishing a sound energy system, and increasing the proportion of high-quality energy such as natural gas and electricity. For the use of new energy, sufficient economic and policy support should be given to establish its strategic position and gradually form a complete new energy industrialization system.

By 2017 Beijing is expected to achieve the goal that high-quality natural gas and electricity account for more than $90 \%$ of energy consumption. By 2020 total energy consumption will remain within 100 million tons of standard coal.

3. Increase the support of government and promote technological innovation

Science and technology are primary productive forces, and technological innovation is essential for reducing carbon emissions. Although Beijing has introduced a series of policies to encourage research and development of low-carbon technologies, the overall need to be further improved exists.

First, adequate financial support is indispensable. Technological innovation is difficult and costly, which relies on the support of research and development funds. The current funds are mainly from the government financial allocation, and the government should increase financial expenditure to promote key technology research efforts. In addition, the single investment mode of financial appropriation should be changed to make flexible use of various market instruments, introduce various financial support, and establish a certain incentive mechanism to encourage the innovation of low-carbon technology.

Second, increase the cooperation between government, universities, and enterprises. Government research institutions are in charge of research on largescale infrastructure projects and provide certain financial and policy support to universities and enterprises to mobilize the enthusiasm of enterprises to participate. Universities are responsible for research and master the forefront of innovative technology topics, and enterprises are responsible for the commercialization of low-carbon technologies and industrialization. Both of them play advantages of themselves and make full use of scientific research and talent resources, and provide strong support for achieving the goal of reducing carbon emissions.

\section{Conclusions}

From the research, the data of per capita $\mathrm{CO}_{2}$ emissions, total energy consumption, energy intensity, and per capita GDP from 1980 to 2015 in Beijing has been selected to construct the curve model of economic development and environmental pollution by means of the symbolic regression method. Based on experimental results and analyses, the following could be concluded:
1. In the study of economic development and environmental deterioration, different measurement methods will get different results; moreover, different models will be determined when different indicators are chosen as variables. The empirical results show that the new M-shaped curve model, the traditional inverted U-shaped curve model, and the less-mentioned L-shaped curve model can be found when per capita $\mathrm{CO}_{2}$ emissions, total energy consumption, and energy intensity are selected as environmental variables to fit the per capita GDP.

2. Although the inverted U-curve model is widely used in the study of environmental and economic issues in previous studies, the empirical results in this paper show that the M-shaped curve model can better describe the relationship between variables, which exposes more details compared to the traditional inverted U-shaped curve model. It can be used as an inverted U-shaped curve of the supplement, refine each stage of the different trends, and be more persuasive.

3. As the capital of China, handling the relationship between economic development and environmental pollution is very important for Beijing. The different development modes in different periods have caused the special curve relationships in Beijing. This paper also analyzes the reasons for this situation. The M-shaped curve model and the inverted U-shaped curve model have reached the peak point, and future development will maintain a downward trend. The L-shaped curve model shows that energy intensity and economic growth have also remained stable. This indicates that Beijing has been aware of the importance of environmental pollution, and that Beijing will also pay more attention to environmental issues in future development. Some measures, such as industrial structure optimization, energy structure adjustment, and technological innovation promotion could better control the air pollution in Beijing.

\section{Acknowledgements}

This work was supported by the Hebei Provincial Social Science Fund Project 2014 (HB15YJ040).

\section{References}

1. IEA. Progress with Implementing Energy Efficiency Policies in the G8. Internal Energy Agency Paper. 2010.

2. CHEN J., CHENG S., SONG M., Wu Y. A carbon emissions reduction index: Integrating the volume and allocation of regional emissions. Applied Energy. 2016.

3. WANG Z., YANG L. Delinking indicators on regional industry development and carbon emissions: BeijingTianjin-Hebei economic band case. Ecological Indicators. 48, 41-48, 2015.

4. WUR.,ZHANG J., BAOY., TONG S. Using a Geographically Weighted Regression Model to Explore the Influencing Factors of $\mathrm{CO}_{2}$ Emissions from Energy Consumption in the 
Industrial Sector. Polish Journal of Environmental Studies. 25, (6), 2641, 2016.

5. CHEN J., CHENG S., SONG M., WANG J. Interregional differences of coal carbon dioxide emissions in China. Energy Policy. 96, 1, 2016.

6. YAN Q., ZHANG Q., ZOU X. Decomposition analysis of carbon dioxide emissions in China's regional thermal electricity generation, 2000-2020. Energy. 112, 788, 2016.

7. MARASENI T.N., QU J., YUE B., ZENG J., MAROULIS J. Dynamism of household carbon emissions (HCEs) from rural and urban regions of northern and southern China. Environmental Science \& Pollution Research. 23 (20), 14, 2016.

8. AHMAD A., ZHAO Y., SHAHBAZ M., BANO S., ZHANG Z., WANG S., LIUA Y. Carbon emissions, energy consumption and economic growth: An aggregate and disaggregate analysis of the Indian economy. Energy Policy. 96, 131, 2016.

9. KUZNETS S. Economic Growth and Income Inequality. The American Economic Review. 45 (1), 1, 1955.

10. SHAFIK N., BANDYOPADHYAY S. Economic Growth and Environmental Quality: Time Series and Cross-Country Evidence. Policy Research Working Paper. 18 (5), 55, 1992.

11. PANAYOTOU T. Demystifying the Environmental Kuznets Curve : Turning a Black Box into a Policy Tool. Environment and Development Economics. 2 (4), 465, 1997.

12. GROSSMAN G.M., KRUEGER A.B. Economic Growth and the Environment. The Quarterly Journal of Economics. 57 (1), 85, 1995

13. AL-MULALI U., TANG C.F., OZTURK I. Estimating the Environment Kuznets Curve hypothesis: Evidence from Latin America and the Caribbean countries. Renewable \& Sustainable Energy Reviews. 50, 918, 2015.

14. ALPER A., ONUR G. Environmental Kuznets curve hypothesis for sub-elements of the carbon emissions in China. Natural Hazards. 82 (2), 1327, 2016.

15. HOLTZ-EAKIN D., SELDEN T.M. Stoking the fires? $\mathrm{CO}_{2}$, emissions and economic growth. Journal of Public Economics. 110 (2), 85, 1995.

16. COLE M.A., RAYNER A.J., BATES J.M. The environmental Kuznets curve: an empirical analysis. Environment and Development Economics. 2, 401, 1997.

17. STERN D.I., COMMON M.S. Is There an Environmental Kuznets Curve for Sulfur?. Journal of Environmental Economics \& Management. 41, 162, 1998.

18. ANSUATEGI A., ESCAPA M. Economic growth and greenhouse gas emissions. Ecological Economics. 40 (1), 23, 2002.

19. DEHNAVI J. Energy consumption, economic growth, and pollution in selected OPEC countries: testing the environmental Kuznets curve hypothesis. Journal of Academic Research in Economics. 4 (2), 149, 2012.

20. ALKHATHLAN K., JAVID M. Energy consumption, carbon emissions and economic growth in Saudi Arabia: An aggregate and disaggregate analysis. Energy Policy. 62 (7), $1525,2013$.

21. WANG .P, WU W., ZHU B., WEI Y. Examining the impact factors of energy-related $\mathrm{CO}_{2}$ emissions using the STIRPAT model in Guangdong Province, China. Applied Energy. 106 (11), 65, 2013.

22. O'NEILL B.C., LIDDLE B., JIANG L., SMITH K.R., PACHAURI S., DALTON M., FUCHS R. Demographic change and carbon dioxide emissions. Lancet. 380 (9837), 157, 2012.

23. XU J., WANG J., WEI Q., WANG Y. Symbolic Regression Equations for Calculating Daily Reference Evapotrans- piration with the Same Input to Hargreaves-Samani in Arid China. Water Resources Management. 30 (6), 2055, 2016.

24. SCHMIDT M., LIPSON H. Distilling free-form natural laws from experimental data. Science. 324 (5923), 81, 2009.

25. KOTANCHEK M.E., VLADISLAVLEVA E.Y., SMITS G.F. Symbolic Regression Via Genetic Programming as a Discovery Engine: Insights on Outliers and Prototype. 55, 2010.

26. YANG G., SUN T., WANG J., LI X. Modeling the nexus between carbon dioxide emissions and economic growth. Energy Policy. 86, 104, 2015.

27. SZELĄG B., GAWDZIK J. Application of Selected Methods of Artificial Intelligence to Activated Sludge Settleability Predictions. Polish Journal of Environmental Studies. 25 (4), 1709, 2016.

28. O'REILLY U. Genetic Programming II: Automatic Discovery of Reusable Programs. Artificial Life. 1 (4), 439, 2010.

29. BATISHCHEVA V., POTAPOV A. Genetic Programming on Program Traces as an Inference Engine for Probabilistic Languages. Lecture Notes in Computer Science. 9205, 14, 2015.

30. LINO A., ÁLVARO ROCHA., SIZO A. Virtual teaching and learning environments: Automatic evaluation with symbolic regression. 31 (4), 2061, 2016.

31. CLAVERIA O., MONTE E., TORRA S. Quantification of Survey Expectations by Means of Symbolic Regression via Genetic Programming to Estimate Economic Growth in Central and Eastern European Economies. Eastern European Economics. 54 (2), 171, 2016.

32. MONTAÑA J.L., ALONSO C.L., BORGES C.E., et al. Model-driven regularization approach to straight line program genetic programming. Expert Systems with Applications. 57, 76, 2016.

33. MURARI A., PELUSO E., GELFUSA M., TIRNAUCA C. Symbolic regression via genetic programming for data driven derivation of confinement scaling laws without any assumption on their mathematical form. Plasma Physics \& Controlled Fusion. 57 (1), 2015.

34. WU C.H., CHOU H.J., SU W.H. Direct transformation of coordinates for GPS positioning using the techniques of genetic programming and symbolic regression. Engineering Applications of Artificial Intelligence. 21 (8), 1347, 2008.

35. SOTTO L., FRAN O., PICCOL O.D., MELO V.V.D. Studying bloat control and maintenance of effective code in linear genetic programming for symbolic regression. Neurocomputing. 180 (C), 79, 2016.

36. CALVETEABA H.I. A new approach for solving linear bilevel problems using genetic algorithms. European Journal of Operational Research. 188 (1), 14, 2008.

37. LINO A., ÁLVARO ROCHA., SIZO A. Virtual teaching and learning environments: Automatic evaluation with symbolic regression. 31 (4), 2061, 2016.

38. ZELINKA I., OPLATKOVA Z., NOLLE L. Analytic programming symbolic regression by means of arbitrary evolutionary algorithm. Simulation. 6 (9), 1473, 2005.

39. JIN Y., SENDHOFF B. Pareto-Based Multiobjective Machine Learning: An Overview and Case Studies. IEEE Transactions on Systems Man \& Cybernetics Part C. 38 (3), 397, 2008.

40. SMITS G.F., KOTANCHEK M. Pareto-Front Exploitation in Symbolic Regression. Genetic Programming Theory and Practice II. Springer US. 8, 283, 2005.

41. IPCC. 2006 IPCC Guidelines for National Greenhouse Gas Inventories: volume II: energy. Japan: Institute for Global Environmental Strategies. 2006. 